\title{
Research on Coordinated Development of Port Logistics and Hinterland Economy in the Middle Reaches of Yangtze River
}

\author{
Chun $\mathrm{Liu}^{1,2}$ \\ ${ }^{1}$ Wuhan Technology and Business University, Department of Management, Wuhan 430065, China \\ ${ }^{2}$ Hubei Collaborative Innovation Center for Modern Logistics and Commerce, Wuhan 430065, China \\ Ic576@126.com
}

Keywords: Urban Agglomerations in the Middle Reaches of the Yangtze River, Port Group, Hinterland, Canonical Correlation Analysis.

\begin{abstract}
During the research time of 2005-2014, this paper selects indicators reflecting the port logistics and its development, indicators reflecting the economic and social development of port hinterland, using canonical correlation analysis method, comprehensive analyzes the interaction development between port logistics urban agglomeration in the Middle Reach of Yangtze River and its hinterland economic, reveal the correlation between the port logistics and hinterland economy development: (1) First typical variable $V_{1}$ embodying hinterland economy development can better predict port cargo throughput, container throughput, the number of berths and waterway freight volume in urban agglomeration in the Middle Reach of Yangtze River; (2) First typical variable $U_{1}$ embodying port logistics can better predict GDP, per capita GDP, the first industry gross domestic product, the second industry gross domestic product, the tertiary industry gross domestic product, total exports, transportation - warehousing and postal service, total retail sales of social consumer goods in urban agglomeration in the Middle Reach of Yangtze River. By the results of the analysis, there is mutually affect and promote each other between port logistics development urban agglomeration in the Middle Reach of Yangtze River and its hinterland economy development.
\end{abstract}

\section{Introduction}

In 2014, the State Council of the PRC proposed to promote the rational distribution of the Yangtze River Economic Belt port, strengthen division of labor, and promote specialization, scale and modernization of the Yangtze River Economic Belt port, and vigorously develop modern shipping services. Strengthen services functions of collecting and distributing of Shanghai, Wuhan and Chongqing as shipping center and main port among the Yangtze River Economic Belt port, expand the scope of radiation to port transportation services ${ }^{[1]}$.

In April 2015, "Development planning of urban agglomeration in the middle reaches of the Yangtze River" pointed out that the middle reaches of the Yangtze River give full play to the advantages of the Yangtze golden waterway, speed up construction of the highway and railroad, transportation system along the Yangtze River, Reasonably promote the shoreline development and port construction, build comprehensive transport system with internal communication and external connection.

In 2016, "Yangtze River economic belt development plan outline" strengthen port collaboration, plan port and harbor as a whole, take the shipping center and main port as the focus, accelerate the construction of connecting line to the railway and highway with important port, enhance the capacity and efficiency of cargo transshipment, achieve the interconnection of hub port with railway and highway transportation ${ }^{[2] .}$

Geerlings ${ }^{[3]}$ (2012) maintain the diversity and complexity of the distribution system in the hinterland of the port is mainly determined by the size of the port and the structure of the goods. With the size of the cargo ship and the scale of the port, resulting in the port hinterland collection and distribution system of multi-channel, all-round and multimodal transport. Konings ${ }^{[4]}$ (2013) explore the Rotterdam 
harbor improve the port container barge loading and unloading capacity by expanding hinterland container transportation. Haezendonck ${ }^{[5]}$ (2014) with stakeholders perspective build port logistics contribution and geographical scope reflect port hinterland correlate with port logistics, use the influence of port hinterland (PHI) matrix, explore the relationship between port logistics contribution and geographical scope. Garcia-Alonso ${ }^{[6]}$ (2016) build the two indexes of Geographical scope and transport consistency, and analyzes the spatial development of port hinterland.

Dong Xiao-fei ${ }^{[7-8]}$ (2010a, 2010b), JIANG Xiao-li ${ }^{[9]}$ (2013) quantitatively research on port hinterland spatial structure in Niaoning province by grey correlation analysis method and the Huff model, reach the spatial structure evolution of port hinterland changing from the single port hinterland to a mixed-hinterland of several ports. WANG Ying ${ }^{[10]}$ (2009), FENG She-miao ${ }^{[11]}$ (2009), YIN Wen-Wei ${ }^{[12]}$ (2009), HU Lie-ge ${ }^{[13]}$ (2013), LI Zhen-fu ${ }^{[14]}$ (2014) and WANG Jie ${ }^{[15]}$ (2014) apply varieties of quantitative methods such as circle theory model, point/axis theory, colony optimization algorithm, least transportation cost method, gravity-fuzzy comprehensive evaluation model, O-D logistics with the method of graph theory, hinterland plume model and density model to define the scope and scale of port hinterland. Fan Hu-guang ${ }^{[16]}$ (2012), LI Tan ${ }^{[17]}$ (2012), ZHENG Jian-ping ${ }^{[18]}$ (2014) respectively study the synergic relationship between port logistics and hinterland economy in Wuhan city, Niaoning province and Sanduao.

This paper mainly used the method of qualitative analysis and quantitative analysis. Combining with the development of port and its hinterland economy from 2005 to 2014 in urban agglomeration in the middle reach of Yangtze river, comprehensive analyze the interactive development between port and its hinterland economy. This paper use canonical correlation analysis, by SPSS software, the two sets of variable data reflecting the development of port and its hinterland economy has carried on the detailed analysis from 2005 to 2014 in the urban agglomeration in the middle reach of Yangtze river, makes clear the quantitative relationship between port and its hinterland economy development. Finally, from view of the interactive development of port and hinterland economy in urban agglomeration in the middle reach of Yangtze river, the urban agglomeration in the middle reach of Yangtze river port and hinterland economy further on the development of interaction. Measures and suggestions to port and hinterland economy further mutual development in urban agglomeration in the middle reach of Yangtze river are proposed.

\section{The development course of port logistics and its hinterland economy in urban agglomeration in the middle reach of Yangtze river}

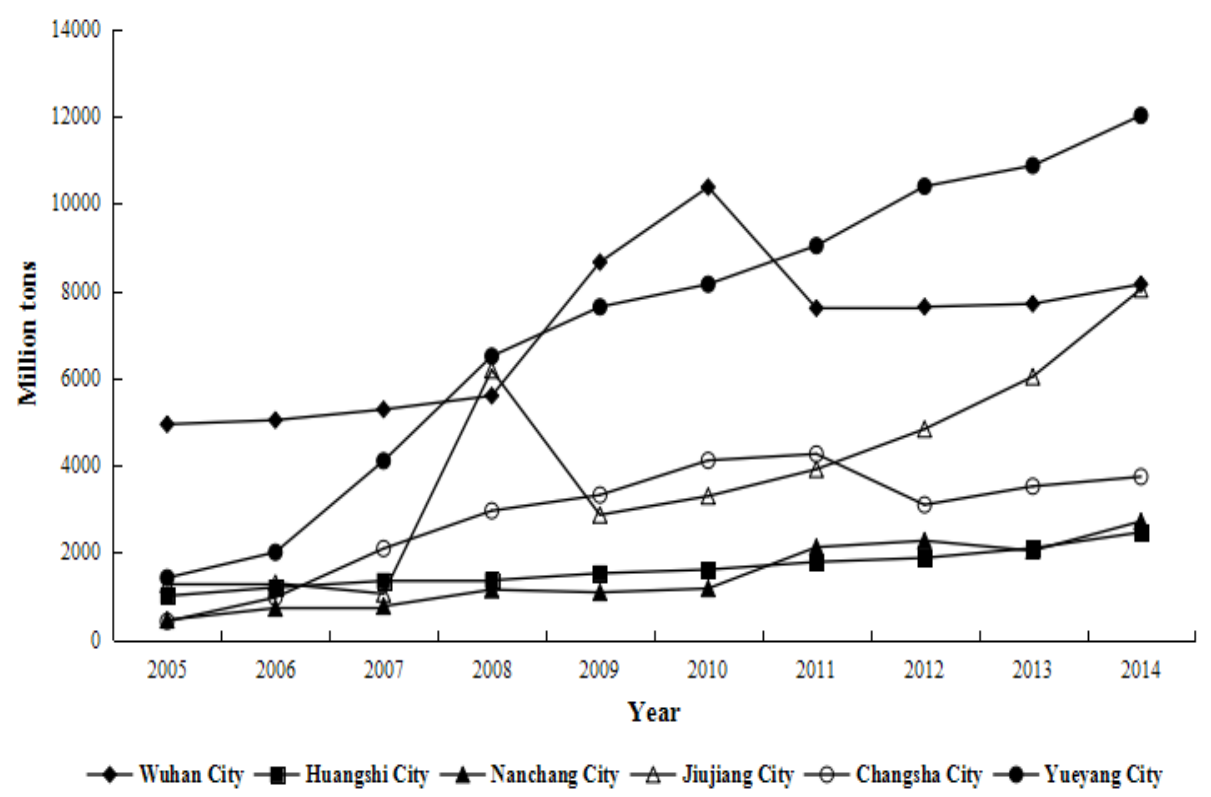

Fig. 1 Cargo Handled at Ports in urban agglomeration in the middle reach of Yangtze river (2005-2014) 
Main ports in urban agglomeration in the middle reach of Yangtze river cover Wuhan port, Huangshi port, Jiujiang port, Nanchang port, Yueyang port, Changsha port, direct hinterland of these ports include three provinces such as Jiangxi province, Hubei province, Hunan province.

As can be seen from the figure 1, during2005-2005, cargo handled at ports of Yueyang, Wuhan and Jiujiang is basically maintain at a high level, far higher than other ports in urban agglomeration in the middle reach of Yangtze river, Jiujiang port grow larger, the growth of Yueyang port and Wuhan port keep the volatility. Cargo Handled at Ports of Changsha, Nanchang, and Huangshi remained at a low level, and grow slowly.

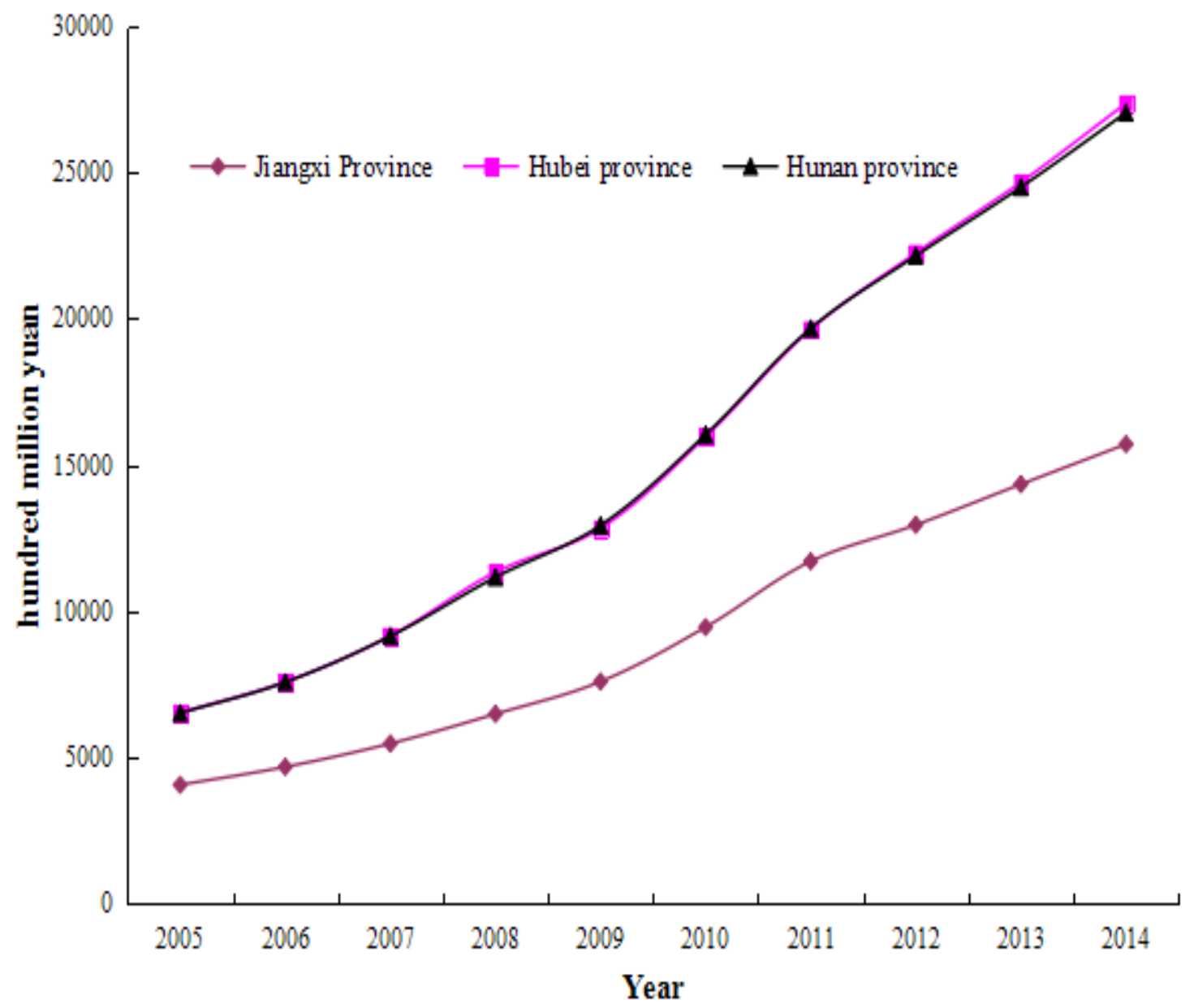

Fig. 2 Gross Domestic Product in Jiangxi province, Hubei province, Hunan province (2005-2014)

From figure 2, GDP growth of both Hubei province and Hunan province during 2005-2014 is synchronized, however higher than that of Jiangxi province. GDP growth trend of three provinces including Jiangxi province, Hubei province, Hunan province is consistent. The relationship among three provinces economic development is very strong. Economic development course of three provinces is divided into two stages: rapid growth stage from 2005 to 2010, and slow growth stage from 2010 to 2014.

From figure 1 and figure 2, during 2005-2014, growth trend of GDP and Cargo handled at main ports in Jiangxi province, Hubei province, Hunan province is consistent. Development track of GDP and Cargo handled at main ports in Jiangxi province, Hubei province, Hunan province has a strong similarity. The above show economic development in urban agglomeration in the middle reach of Yangtze river was related to economic development at home and abroad during this period.

\section{Canonical correlation analysis model between port logistics and hinterland economy}

In 1936, Hotelling first proposed the canonical correlation analysis method used to study the correlation between a set of random variables and other a set of random variables. This method embody the idea of principal component analysis, and according to the correlation between the 
variables, search one or a few aggregate variables ( linear combination of the actual observed variables) to replace the raw variables, which will lead to the correlation between the two sets of variables substitute for the relationship among a few aggregate variables ${ }^{[19]}$.

Port indicators selected by this paper include the indicator of cargo handled at ports reflecting the size of the port cargo, and the indicator of container handled embodying dominate container shipping in the modern transportation, the indicator of waterway freight traffic reflecting the development of port because of many rivers in urban agglomeration in the middle reach of Yangtze river. $x_{1}-x_{3}$ in table 1 express the indicators reflecting the scale and the development of port.

Tab.1 Port and hinterland economy indicators reflecting interaction with each other

\begin{tabular}{cc}
\hline Port indicators & Hinterland economy indicators \\
\hline $\begin{array}{c}\text { Cargo Handled at Ports(10000 tons) } x_{1} \\
\text { Container Handled(10000 TEU) } x_{2} \\
\text { Waterway Freight Traffic(10000 } \\
\text { tons) } x_{3}\end{array}$ & Gross Domestic Product(100 million yuan) $y_{1}$ \\
& Primary Industry Gross Domestic Product(100 million yuan) \\
$y_{3}$ & Secondary Industry Gross Domestic Product(100 million \\
yuan) $y_{4}$ \\
Tertiary Industry Gross Domestic Product(100 million yuan) \\
\\
Total Value of Imports and Exports of Goods(USD 100 \\
million) $y_{6}$ \\
\\
Total Value of Exports of Goods(USD 100 million) $y_{7}$ \\
Length of Expressway and Class I to IV Highway(km) $y_{8}$ \\
Transport, Storage and Post GDP(100 million yuan) $y_{9}$ \\
Total Retail Sales of Consumer Goods(100 million yuan) $y_{10}$ \\
\hline
\end{tabular}

In view of the availability and accuracy of the data, this paper about the indicators system of hinterland economy mainly selects Gross Domestic Product (GDP) measuring comprehensive level of region economic development, Per Capita GDP as the indicator of economic development, Primary Industry Gross Domestic Product, Secondary Industry Gross Domestic Product, Tertiary Industry Gross Domestic Product in order to more accurately analyze the relationship between the development of the port and the hinterland, Total Value of Imports and Exports of Goods, Total Value of Exports of Goods reflecting the development of foreign trade of the hinterland in international trade dependent on water freight, Length of Expressway and Class I to IV Highway, Transport, Storage and Post GDP representative for collecting and distributing of hinterland, Total Retail Sales of Consumer Goods reflecting the market prosperity of the hinterland, and furthermore the relationship between the development of port and hinterland economy. $y_{1-} y_{10}$ in table 1 express the indicators reflecting the economic and social development situation of hinterland.

In view of the availability and accuracy of the data, this paper choose data of port indicators about Wuhan port, Huangshi port, Jiujiang port, Nanchang port, Yueyang port, Changsha port in urban agglomeration in the middle reach of Yangtze river, and data of hinterland indicators about Jiangxi province, Hubei province, Hunan province.

\section{Empirical study on coordinated development of port logistics and hinterland economy in the Middle Reaches of Yangtze River}

4.1 The correlation coefficient between both variables of port cluster and hinterland economy

Analysis of the intraclass correlation coefficients between ports development indicators show, correlation coefficient between $\mathrm{x} 1$ and $\mathrm{x} 3$ is 0.8032 explains there is a strong correlation between Cargo Handled at Ports and Waterway Freight Traffic, which is consistent with the actual situation. At the same time, the correlation coefficient between indicators is larger, that suggests that the indicators 
selected has a certain repeatability, thus furthermore, the indicators selected as port development is reasonable.

Analysis of the correlation coefficients between hinterland economic development indicators show, correlation coefficient between y1 and y3 is 0.9828 explains there is a strong correlation between Gross Domestic Product and Tertiary Industry Gross Domestic Product in urban agglomeration in the middle reach of Yangtze river, which also shows that Tertiary Industry Gross Domestic (such as transportation, post and telecommunications, business, catering, material supply and marketing and warehousing, tourism and other departments ) play a very important position in economic development.

Tab.2 The correlation coefficient between both variables of port and hinterland economy

\begin{tabular}{ccccccccccc} 
& $y_{1}$ & $y_{2}$ & $y_{3}$ & $y_{4}$ & $y_{5}$ & $y_{6}$ & $y_{7}$ & $y_{8}$ & $y_{9}$ & $y_{10}$ \\
\hline$x_{1}$ & 0.8418 & 0.7521 & 0.8554 & 0.8164 & 0.8465 & 0.5399 & 0.4526 & 0.8724 & 0.854 & 0.7901 \\
$x_{2}$ & 0.6673 & 0.6992 & 0.6314 & 0.6701 & 0.6568 & 0.6565 & 0.5368 & 0.7262 & 0.6029 & 0.7925 \\
$x_{3}$ & 0.8307 & 0.6885 & 0.9040 & 0.7731 & 0.8577 & 0.3994 & 0.2606 & 0.8878 & 0.8425 & 0.8746 \\
\hline
\end{tabular}

Table 2 shows the correlation coefficient between 3 variables of port and 10 variables of hinterland economic development. From table 2 can be found that the correlation coefficient between the two sets of indicators exists large fluctuations, the correlation coefficient maximum value between Waterway Freight Traffic and Primary Industry Gross Domestic Product is 0.9040 , the correlation coefficient minimum value between Waterway Freight Traffic and Total Value of Exports of Goods is 0.2606. The direct relevance between both two sets of port indicators and hinterland economic development indicators is little. So to a great extent, the correlation between the two depend on two sets of indicators integrated with each other. On account of the interaction between two sets of variables, the simple correlation coefficient matrix of table 2 can only be used as a reference, not really reflect the essential relationship of between two sets of variables. So, to explore the substantial relationship between two sets of variables, need further canonical correlation analysis.

\subsection{Canonical correlation coefficient and test of significance}

Tab.3 Canonical correlation coefficient and test of significance

\begin{tabular}{cccccc}
\hline & correlation coefficient & Wilk's & Chi-SQ & DF & Sig. \\
\hline 1 & 0.998 & 0.000 & 185.986 & 30.000 & 0.000 \\
2 & 0.926 & 0.044 & 68.750 & 18.000 & 0.000 \\
3 & 0.832 & 0.308 & 25.883 & 8.000 & 0.001 \\
\hline
\end{tabular}

As can be seen from table 3, three sets of canonical correlation coefficients were extracted, the first canonical correlation coefficient is 0.998 , the second is 0.926 , the third is 0.832 . The first and second canonical correlation coefficient is higher than any correlation coefficient of the two sets of port and hinterland economic development. Therefore, the comprehensive effect of canonical correlation analysis is better than simple correlation analysis.

Canonical correlation coefficient is from sample data to calculate, and like simple correlation coefficient, there is also the need for hypothesis test. In this paper, using Bartlett $\chi^{2}$ test, null hypothesis for the corresponding canonical correlation coefficient is 0 . First column of table 3 is correlation coefficient, from left to right respectively is Wilks's $\lambda$ statistics, chi-square statistic, degree of freedom and significance. Test results can be summarized that significant probability of the first, second, third correlation coefficient is less than 0.005 , in the case of $\alpha=0.05$, the hypothesis that canonical correlation coefficient is zero is denied. The above illustrate the canonical correlation between three sets of variables is significant.

From the above analysis results, the correlation study of the indicators between port and hinterland economic can be converted into the correlation study of the variables between the first canonical correlation and the second. 


\subsection{Canonical variables coefficients}

Tab.4 Standardized canonical coefficients for port variables

\begin{tabular}{cccc}
\hline & 1 & 2 & 3 \\
\hline$x_{1}$ & -0.164 & 0.678 & 1.578 \\
$x_{2}$ & -0.783 & -0.890 & 0.642 \\
$x_{3}$ & -0.175 & 0.531 & -1.982 \\
\hline
\end{tabular}

Because of not the same dimensions of variables of the port and hinterland economy, it is best to use standardized coefficient of variables. Two sets of standardized canonical variable coefficient can be used to study the correlation of the indicators between the port and hinterland economy development.

By table 4 can be known, the first standardized canonical variable of port calculation formula for $U_{1}=-0.164 x_{1}-0.783 x_{2}-0.175 x_{3}$

Tab.5 Standardized canonical coefficients for hinterland economy variables

\begin{tabular}{lccc}
\hline & 1 & 2 & 3 \\
\hline$y_{1}$ & 111.587 & 2196.781 & 6892.073 \\
$y_{2}$ & -0.774 & -0.585 & -2.903 \\
$y_{3}$ & -12.803 & -245.556 & -774.857 \\
$y_{4}$ & 52.760 & -1069.430 & -3352.450 \\
$y_{5}$ & -44.280 & -901.936 & -2838.780 \\
$y_{6}$ & -0.357 & -0.856 & -0.175 \\
$y_{7}$ & 0.156 & 0.691 & 1.476 \\
$y_{8}$ & -0.404 & 0.860 & 1.293 \\
$y_{9}$ & -0.305 & 0.606 & 2.439 \\
$y_{10}$ & -2.192 & -3.252 & -0.234 \\
\hline
\end{tabular}

By table 5 can be known, the first standardized canonical variable of hinterland economy development calculation formula for

$$
\begin{aligned}
& V_{1}=111.587 y_{1}-0.774 y_{2}-12.803 y_{3}+52.760 y_{4}-44.280 y_{5}-0.357 y_{6}+0.156 y_{7} \\
& -0.404 y_{8}-0.305 y_{9}-2.192 y_{10}
\end{aligned}
$$

In the same way, the first standardized canonical variable of port calculation formula for $U_{2}=0.678 x_{1}-0.890 x_{2}+0.531 x_{3}$

The first standardized canonical variable of hinterland economy development calculation formula for

$$
\begin{aligned}
& V_{1}=2196.781 y_{1}-0.585 y_{2}-245.556 y_{3}-1069.430 y_{4}-901.936 y_{5}-0.856 y_{6} \\
& +0.691 y_{7}+0.860 y_{8}+0.606 y_{9}-3.252 y_{10}
\end{aligned}
$$

\subsection{Analysis on the canonical structure}

Analysis on the canonical structure is to analyze the correlation degree between the raw variables and canonical one. Canonical loadings represents the correlation between a set of raw variables and their corresponding canonical variables, canonical loadings for port represents the correlation between a set of raw port variables and their corresponding canonical variables $U_{1}$ (figure 3 ). In the first set of canonical variables, all indicators of the port are positively correlated with the canonical variables of port, which is in line with the actual situation. Canonical loadings for hinterland economy development 
represents the correlation between a set of raw hinterland economy development variables and their corresponding canonical variables $V_{1}$. All indicators except for $y_{3}$ of the hinterland economy development are positively correlated with the canonical variables of hinterland economy development. There is a negative correlation between Primary Industry Gross Domestic Product and the canonical variables of the hinterland economy.

The correlation coefficient between a raw variable and a canonical one, which is contrary to that of the raw variable on the canonical variable. However, in the case of a close correlation between multiple raw variables, this is normal. This is similar to the multicollinearity in regression analysis, which can be found by canonical structure analysis in canonical correlation analysis.

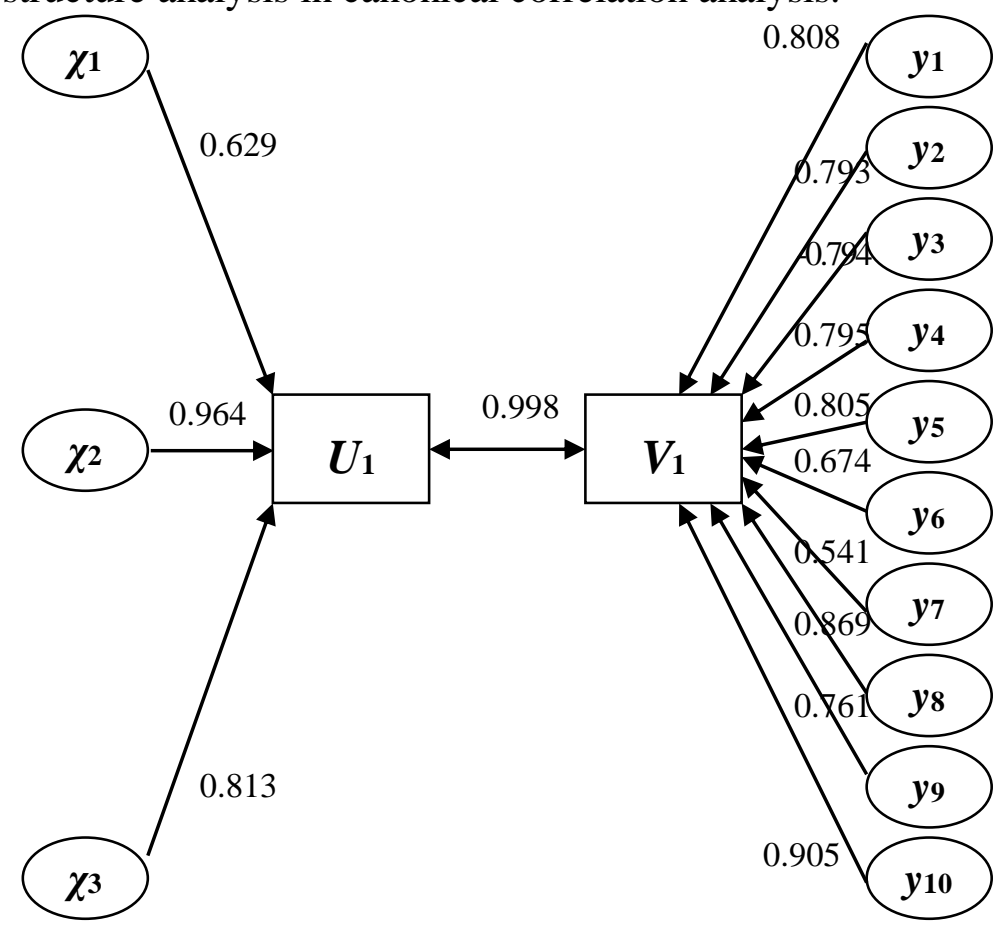

Fig.3 Canonical structure chart of standardized canonical coefficients for set-1

The cross loadings coefficient represents the relationship between a set of raw indicators and their opposite canonical variables, which can be used to judge whether a set of raw indicators can be predicted by their opposite canonical variables. In this paper, the canonical variable $U_{1}$ of port predict the raw indicators of hinterland economic development, or the canonical variable $V_{1}$ of hinterland economic development predict the raw indicators of port, which is very important.

Tab.6 Cross loadings for port

\begin{tabular}{cccc}
\hline & 1 & 2 & 3 \\
\hline$x_{1}$ & 0.627 & 0.681 & 0.210 \\
$x_{2}$ & 0.962 & -0.246 & 0.011 \\
$x_{3}$ & 0.811 & 0.463 & -0.249 \\
\hline
\end{tabular}

Known from table 6 , the canonical variable $V_{1}$ of hinterland economic development can better predict $x_{1}, x_{2}$ and $x_{3}$. The correlation coefficient is respectively $0.627,0.962$ and 0.811 , the coefficient of determination is respectively $0.393,0.925$ and 0.658 . 
Tab.7 Cross loadings for hinterland economy

\begin{tabular}{cccc}
\hline & 1 & 2 & 3 \\
\hline$y_{1}$ & 0.806 & 0.418 & 0.111 \\
$y_{2}$ & 0.791 & 0.253 & 0.271 \\
$y_{3}$ & -0.792 & 0.498 & -0.036 \\
$y_{4}$ & 0.794 & 0.368 & 0.187 \\
$y_{5}$ & 0.803 & 0.445 & 0.058 \\
$y_{6}$ & 0.672 & -0.006 & 0.482 \\
$y_{7}$ & 0.540 & -0.032 & 0.543 \\
$y_{8}$ & 0.867 & -0.417 & 0.084 \\
$y_{9}$ & 0.759 & 0.490 & 0.065 \\
$y_{10}$ & 0.903 & 0.295 & 0.022 \\
\hline
\end{tabular}

Known from table 7, the canonical variable $U_{1}$ of port indicators can better predict $y_{1}, y_{2}, y_{3}, y_{4}$, $y_{5}, y_{7}, y_{8}, y_{9}$ and $y_{10}$. The correlation coefficient is respectively $0.806,0.791,-0.792,0.794,0.803$, $0.672,0.540,0.867,0.759$ and 0.903 , the coefficient of determination is respectively $0.650,0.626$, $0.627,0.630,0.645,0.452,0.292,0.752,0.576$ and 0.815 .

\subsection{Canonical redundancy analysis}

The canonical redundancy analysis is used to represent the degree of variation of each variable to the raw variable set, which is divided into two sets: variation of within and between. By the canonical redundancy analysis. $60.6 \%$ proportion of within variation of port indicators set is explained by the first canonical variable $U_{1}$ of port indicators. $13.2 \%$ proportion of within variation of port indicators set is explained by the second canonical variable $U_{2}$ of port indicators. $65.9 \%$ proportion of within variation of hinterland economic development indicators set is explained by the first canonical variable $V_{1}$ of hinterland economic development indicators. $24.6 \%$ proportion of within variation of hinterland economic development indicators set is explained by the second canonical variable $V_{2}$ of hinterland economic development indicators.

From the above analysis results, within variation of port indicators set and hinterland economic development indicators set can be well explained by the first canonical variable. But indicators set of port and hinterland economic development can be poor explained by the second canonical variable of port. Indicators set of port and hinterland economic development can be well explained by the second canonical variable of hinterland economic development. Therefore, we should focus on the analysis of the first set of canonical variables.

\section{Conclusion}

According to the analysis results, it is known that the development of the port of the middle reaches of the Yangtze River is closely related to the development of the hinterland economy. The construction and development of the port and hinterland economy are mutual influence and mutual promotion. The canonical variable $V_{1}$ of hinterland economic development can better predict cargo handled at ports, container handled and waterway freight traffic. Therefore, based on the data of the hinterland economic development, we can predict the size of the corresponding ports, put forward the reasonable construction plan of the port clusters. In the same way, the canonical variable $U_{1}$ of port indicators can better predict Gross Domestic Product (GDP), Per Capita GDP, Primary Industry Gross Domestic Product, Secondary Industry Gross Domestic Product, Tertiary Industry Gross Domestic Product, 
Total Value of Exports of Goods, Transport, Storage and Post GDP and Total Retail Sales of Consumer Goods. Based on the data of the port clusters, we can predict the hinterland economic development meet the extent of the development of the port clusters, in order to reasonably establish the strategy and measures of the hinterland economic development.

\section{Acknowledgments}

This work was financially supported by Scientific Research Plan Guidance Project for Hubei Provincial Department of Education (B2016334) fund, China Logistics Association, China Federation of Logistics and Purchasing Research Project(2015CSLKT3-145)fund.

Corresponding author: LIU Chun, Wuhan Technology and Business University, Department of Management, Wuhan 430065, CHINA

\section{References}

[1] State Council of the PRC. Guiding Opinions on Promoting the Development of Yangtze River Economic Belt Based on Gold Waterway [EB/OL].
[ http://www.gov.cn/zhengce/content/2014-09/25/content_9092.htm, 2014-09-12/2016-09-10.

[2] "Yangtze River economic belt development plan outline" issued to build a comprehensive three-dimensional corridor[EB/OL]. http://www.chinanews.com/cj/2016/09-13/8002435.shtml, 2016-10-03/2016-09-13.

[3] Geerlings, H., Lohuis, J.B., Shiftan, Y. Transition Management: a new opportunity to introduce new policy concepts for transport policy-making. In: Geerlings, H., Shiftan, Y. (Eds.), Transition towards Sustainable Mobility: the Role of Instruments, Individuals and Institutions. Ashgate Publishers, London, 2012: 13-32.

[4] Konings R.,Kreutzberger E.,Maras V. Major considerations in developing a hub-and-spoke network to improve the cost performance of container barge transport in the hinterland: the case of the port of Rotterdam [J]. 2013, 29(765):63-73

[5] Haezendonck E.,Dooms M.,Verbeke A. A new governance perspective on port-hinterland relationships: The Port Hinterland Impact (PHI) matrix [J]. Maritime Economics \& Logistics, 2014, 16(3):229-249

[6] Garcia-Alonso L.,Martinez-Pardo A.,Vallejo-Pinto J.A. Analysis of the spatial development of the hinterland of ports: a case study [J]. International Journal Of Shipping And Transport Logistics, 2016, 8(2):111-128.

[7] Dong Xiao-fei, Wang Rong-cheng, Han zeng-lin. Study On The Spatial Structure Evolution Of Port- Hinterland System:Tahing Dalian Port- Liaoning Economic Region As An Example [J]. ECONOMIC GEOGRAPHY, 2010a, 30(11): 1761-1766.

[8] Dong Xiao-fei, Wang Rong-cheng, Han zeng-lin. Study on the Correlation Spatial Evolution of Dalian Port Liao ning Hinterland System [J]. Areal Reserch and Development, 2010b, 29(6): 29-33.

[9] JIANG Xiao-li, ZHANG Ping-yu. The Hinterland Evolution of Liaoning Coastal Ports Based on The Huff Model [J]. SCIENTA GEOGRAPHICA SINICA, 2013, 33(3): 282-289.

[10] WANG Ying, WANG Jian. The Dimensional Structure Model of Partitioning Seaport Hinterland in West Coast of the Taiwan Straits Port Group_From the Perspective of Economic Geography[J]. Journal of Fujian Normal University(Philosophy and Social Sciences Edition), 2009(5): 49-55.

[11] FENG She-miao. Partitioning model for port indirect hinterland based on ant colony optimization algorithm[J]. Port \& Waterway Engineering, 2009(5): 47-20.

[12] YIN Wen-Wei, MOU Dun-guo. Analysis Of The Ningbo-Zhoushan Port Hinterland And The Meaning To Port Economy Devolopement [J]. ECONOMIC GEOGRAPHY, 2011, 31(3): 447-452. 
[13] HU Lie-ge, DUAN Juan. The Comparison of Two Kinds of Range Partitioning Method of Port Economic Hinterland: An Approach to Realize Two-type Development of Port Areas [J]. Systems Engineering, 2013, 31(2): 37-41.

[14] LI Zhen-fu, TANG Xiao-wen. The Hinterland Plume Model of Port Hinterland Segmentation [J]. SCIENTA GEOGRAPHICA SINICA, 2014, 34(10): 1169-1175.

[15] WANG Jie,WANG Xiao-bin,ZHANG Mi-ni. Port hinterland segmentation model based on GIS [J]. Port \& Waterway Engineering, 2014(10): 91-96.

[16] Fan Hu-guang, Jiang Hui-yuan, Tian Xiao-yong, Shen huang. Cointegration on the Relationship of Port Logistics and Economic Development in the Core Hinted and Illustrated [J]. Journal of Wuhan University of Technology (Transportation Science \& Engineering), 2012, 36(3): 537-540.

[17] LI Tan, WANG Li, WANG Yu. Research on Synergetic Development Between Efficiency of Port Logistics and Its Hinterland Economy in Liaoning Province [J]. ECONOMIC GEOGRAPHY, 2012, 32(9): 108-113.

[18] ZHENG Jian-ping. The Analysis of the Synergic Relationship between Sanduao Port Logistics and Ningde Hinterland Economy [J]. Logistics Sci-Tech, 2014, 37(8): 48-51.

[19] HE Man-xi. The Study of Relations between Transportation and Economic Development Based on Canonical Correlation Analysis [J]. Ecological Economy, 2014, 30(1): 100-103. 